\title{
Acute and Long-term Effects of Saxagliptin on a Set of Cardiovascular Targets Measured at Fasting and Post-prandially in Obese Patients With Impaired Glucose Tolerance: a Randomized, Placebo-controlled, Double-blind Study
}

\author{
Amel Rezki \\ Universite Paris 13 \\ Emmanuel Cosson \\ Universite Paris 13 \\ Marinos Fysekidis \\ Universite Paris 13 UFR de Sante Medecine Biologie Humaine \\ Sabrina Chiheb \\ Hopital Jean Verdier \\ Eric Vicaut \\ Hopital Fernand-Widal \\ Paul Valensi ( $\sim$ paul.valensi@aphp.fr) \\ Hopital Jean-Verdier Service d'Endocrinologie Diabetologie et Nutrition
}

\section{Original investigation}

Keywords: impaired glucose tolerance, arterial stiffness, autonomic nervous system, dipeptidyl peptidase inhibitor, endothelium, microcirculation, postprandial, standardized meal, saxagliptin

Posted Date: September 9th, 2020

DOI: https://doi.org/10.21203/rs.3.rs-58025/v1

License: @ (i) This work is licensed under a Creative Commons Attribution 4.0 International License. Read Full License 


\section{Abstract}

Background: Studies of dipeptidyl peptidase inhibitors (DPP4is) report heterogeneous effects on cardiovascular targets in type 2 diabetes. Little is known about the cardiovascular effects of DPP4is in patients with impaired glucose tolerance (IGT) in particular during the post-prandial state.

Methods: In this randomized, placebo-controlled, double-blind, single-center pilot study, we included obese individuals with IGT. Participants were randomized to receive for 12 weeks either saxagliptin $5 \mathrm{mg}$ a day or placebo. They were explored non-invasively before and after a standardized breakfast for biological markers; microcirculatory blood flow at baseline and after transcutaneous administration of acetylcholine (Periflux System 5000® PERIMED); post-occlusive digital reactive hyperhemia (Endopat2000®); pulse wave velocity, augmentation index, central pulse pressure and subendocardial viability ratio (Sphygmocor®); cardiac hemodynamic parameters and cardiovascular autonomic nervous system activity (Task force monitor ${ }^{\circledR}$ ).

Results: We investigated 24 individuals (mean body mass index $36.8 \pm 4.8 \mathrm{~kg} / \mathrm{m}^{2}$, hypertension $33.3 \%$ ). The results of all the investigations were similar after breakfast in the two groups at Visit 1 (acute post-prandial effects, after the first tablet) and Visit 2 (long-term post-prandial effects), and at fasting at Visit 1 and 2 (long-term effects, after 12 weeks of treatment). Only at Visit 2 the decrease in cardiac vagal activity occurring after breakfast was more sustained in the saxagliptin group than in the placebo group (interaction between treatment and time effect: $p=0.016$ ).

Conclusion: In obese patients with IGT, among the large set of cardiovascular parameters we measured in the fasting and post-prandial state, the unique change induced by saxagliptin consisted in a more marked post-prandial depression of vagal activity.

Clinical Trial Registration number: NCT01521312

\section{Background}

Patients with type 2 diabetes are still at high cardiovascular risk despite marked improvement in care management (1). Residual risk is partly attributed to glycaemic variability, especially due to spikes of glucose exposure after meals (2). Indeed, several cardiovascular changes occur during post-prandial phase (3). Likewise, people with impaired glucose tolerance (IGT) have a higher cardiovascular risk than those with fasting hyperglycaemia, another prediabetic state (4).

Some pharmacological glucose-lowering therapies such as sodium/glucose cotransporter 2 inhibitors and glucagon-like peptide 1 (GLP-1) receptor agonists have recently shown that they could reduce cardiovascular burden in patients with type 2 diabetes (5). Di-peptidyl peptidase 4 inhibitors (DPP4is) provide protection for the incretin hormones GLP-1 and gastric inhibitory polypeptide from enzymatic degradation by DPP-4 and improve meal-stimulated insulin secretion by pancreatic beta cells (6-9). This class had shown some potential beneficial cardiovascular effects at fasting when the current study was designed $(10,11)$. These beneficial effects were then confirmed in many studies, including anti-inflammatory effects (12), improvement of endothelial function (6,12-14), no abnormalities indicative of cardiac injury (15) and possibly some anti-hypertensive effects $(6,16,17)$. Here, we designed this study to investigate whether saxagliptin, a DPP4i, had beneficial cardiovascular effects not only at fasting but also post-prandially. For this, we investigated endothelial function, microcirculation, arterial stiffness, cardiac contractile function and autonomic nervous system activity before and after a standardized breakfast.

Our results are important because since we began the study, although randomized controlled studies have shown that several DPP4is including saxagliptin were safe and neutral in type 2 diabetes patients at high cardiovascular risk $(12,18)$, saxagliptin treatment was associated with an increased rate of hospitalizations for acute heart failure $(18,19)$. This increase was not observed with other DPP4is $(12)$, and whether this was a class effect is still debated $(12,15,20)$. Therefore, the impact of saxagliptin on heart failure remains controversial $(20)$ and our study could provide some clues regarding the potential mechanisms involved.

\section{Methods}

\section{Study design}

The "ACute and Chronic Effects of Saxagliptin" (ACCES) study is a randomized, placebo-controlled, double-blind, controlled phase 2, pilot study conducted at Jean Verdier University Hospital (Bondy, France). The study was approved both by the local ethics committee (Comité de Protection des Personnes, Reference Number: JLD/AP-protocole 27-2011) and the French National Agency for Drug Security (Agence Nationale de Sécurité du Médicament, Number: A110912-14) and was registered as a clinical trial (NumberEudraCT: NCT01521312).

There were two parts in this study. The first one explored acute and long-term effects of saxagliptin vs placebo on glucose tolerance (ACCES-Glucose study), the results of which will be reported elsewhere. The second part explored the effects of saxagliptin vs placebo on vascular parameters (ACCES-Vasc study) which are shown in the present article.

\section{Study population}

The inclusion criteria were the following: patients with healthcare insurance, diagnosed with IGT according to an oral glucose tolerance test (OGTT) performed less than 3 weeks before the inclusion, age between 18 years and 70 years, body mass index ranging from 30 to $40 \mathrm{~kg} / \mathrm{m}^{2}$. Exclusion criteria were the following: pregnancy or absence of contraception in women of childbearing age, breastfeeding women, known diabetes (defined as fasting plasma glucose $(F P G) \geq 7 \mathrm{mmol} / \mathrm{L}$ or 2 hours after OGTT $\geq 11.1 \mathrm{mmol} / \mathrm{L}$ ) (21), uncontrolled hypertension (defined as blood pressure (BP) $\geq 160 / 110 \mathrm{mmHg}$ ), dyslipidemia (defined as serum total cholesterol $>6.5 \mathrm{mmol} / \mathrm{l}$, or triglycerides $>2.3 \mathrm{mmol} / \mathrm{l}$ ), renal failure (creatinine clearance $<60 \mathrm{ml} / \mathrm{min}$ ), hepatic failure (prothrombin time $<70 \%$ ), chronic respiratory disease, anemia (hemoglobin level $<10 \mathrm{~g} / \mathrm{dl}$ ), cardiac failure (from grade 2 of the NYHA classification), lower limb arterial 
disease (intermittent claudication, absence of lower limb peripheral pulses or ankle brachial pressure index $<0.8$ ), cardiac arrhythmia, anti-hypertensive or current lipid-lowering treatment initiated after the diagnosis of IGT, hypersensitivity to saxagliptin or any excipients (lactose monohydrate, microcrystalline cellulose (E460i), croscarmellose sodium (E468), magnesium stearate), and patients who had previously experienced a severe hypersensitivity reaction to a DPP4i. Smoking was possible and defined as present if patient continued to smoke or had stopped for $<3$ years ago.

The methods used were non-invasive. All patients gave us their agreement and signed the informed consent according to the European directives.

The anticipated effect size $(\Delta / \sigma)$ for our study was estimated at 1.1 , the power level was $80 \%$ and the probability level was set at 0.05 . The estimated minimum sample size for a two-tailed hypothesis was calculated at 12 persons per group.

All participants were admitted for routine checkup for obesity to the research department of Endocrinology Diabetology and Nutrition. They were free of any acute disease at the time of screening for hyperglycemia. The OGTT was performed within one to three weeks before inclusion in all subjects with $75 \mathrm{~g}$ of carbohydrates after night's fasting of 12 hours. IGT was defined as 2-hour post-OGTT plasma glucose value $\geq 7.8 \mathrm{mmol} / \mathrm{L}$ and $<11.1 \mathrm{mmol} / \mathrm{L}$, with a FPG value $<7 \mathrm{mmol} / \mathrm{L}$ (21). Participants received dietary advices during the pre-inclusion period.

\section{Study protocol}

From September 2012 to September 2014, we included 24 subjects. The investigations were non-invasive and performed twice: first at inclusion (Visit 1 ) and second, 12 weeks after inclusion (Visit 2). Also, women of childbearing age had a plasma blood pregnancy test the day before investigations to rule out any current pregnancy. Subjects were randomized to treatment with saxagliptin or placebo for 12 weeks, and treatment attribution was double blinded.

Smokers were asked not to smoke before and during the visits. At Visit 1, saxagliptin or placebo treatment was taken after the fasting blood sampling, 30 minutes before eating the standardized breakfast. Thus, the measurements at fasting during visit 1 were performed in both groups before taking the experimental treatment. During the rest of the study the experimental treatment was taken immediately before breakfast.

At Visit 1 and 2, the measurements were conducted at an ambient temperature of $22^{\circ} \mathrm{C}$ to $24^{\circ} \mathrm{C}$ in a room where noise and light were kept to a minimum. Participants remained at rest in the supine position throughout the tests. All cardiovascular tests were non-invasive and were performed at fasting and 60 and 120 minutes after breakfast.

Participants were contacted for follow-up by telephone to note any side effect. Visit 2 followed the same study protocol as Visit 1 . Patients were advised not to change their daily physical activity during the study period. Urinary pregnancy tests were performed at the hospital every month and at any time during the study in case of late menstruation. Visit 3 (three to five days after Visit 2) included measurements of glucose levels before and 2 hours after OGTT and HbA1c. The participation in the study stopped after that visit (Figure 1).

\section{Procedures during Visit 1 and Visit 2}

\section{- Standardized breakfast}

As previously reported (22) this standardized breakfast contained $75 \mathrm{~g}$ of carbohydrates. It consisted of unsweetened coffee or tea (200 $\mathrm{ml}$ ), $200 \mathrm{ml}$ of orange juice and $60 \mathrm{~g}$ of white bread with $30 \mathrm{~g}$ of jam and was offered to the patient who was asked to eat it in 10 minutes.

\section{- Biological measurements}

The biological assessments were performed at fasting and after the standardized breakfast (Figure 1). Plasma glucose was assessed by the oxidase method (colourimetry, Kone Optima, Thermolab System, Paris La Défense, France) at fasting and one, two and three hours after the breakfast, and HbA1c was measured (agarose electrophoresis; HYRYS, HYDRASYS, Sebia, Evry, France). Serum samples were centrifuged at $-4{ }^{\circ} \mathrm{C}$ and stored at $-80{ }^{\circ} \mathrm{C}$. These samples were used for an enzyme-linked immunosorbent assay to measure nitrotyrosin (Cell Biolabs, San Diego, CA, USA), E-selectin (R\&D Systems, Abingdon, UK) and vascular cell adhesion molecule-1 (VCAM-1; R\&D Systems, Abingdon, UK) according to the manufacturer's instructions. Laser immunonephelometry (BN100; Dade-Behring) was used to measure the UAER from urine specimens.

\section{- Microcirculatory cutaneous blood flow measurement}

Cutaneous blood flow (CBF, expressed as perfusion units) was measured at baseline for 6 min and during 1 min of paced breathing ( 6 breaths/min) on the forearm, using laser Doppler flowmetry (Periflux System 5000®, PERIMED, Sweden). CBF changes during the 1 min of paced breathing (expressed as \%) reflect microvascular autonomic activity, with CBF decreasing during inhalation due to sympathetic nervous system activation. The percentage decrease in the signal wavelet from the zenith to nadir was calculated, and the mean decrease during the three last breaths was used as the index of microvascular sympathetic activity as previously described $(22,23)$.

Changes in CBF after transcutaneous administration of acetylcholine (Ach: Miochol-E®, 20mg of Ach chloride/vial; CHAUVIN®, topical application of 4 mg) through iontophoresis were also measured to explore endothelial function. Ach chloride was diluted in $1 \mathrm{~mL}$ of sterile water, after which $200 \mu \mathrm{L}$ of this solution was placed into a special chamber of a sponge that was used for skin application. After Ach administration, we measured (i) maximal CBF, (ii) delay from Ach administration to maximal CBF (peak delay) and (iii) CBF incremental area under the curve 10 min after Ach administration, which is considered an index of microvascular endothelial function (22). 
Arterial endothelial function was assessed in one of the digital arteries by recording finger arterial pulsatile volume changes for 15 min using the Endopat2000® system (Itamar Medical ${ }^{\circledR}$, Israel), which uses plethysmographic biosensors. Reactive hyperhemia was measured after occluding brachial artery blood flow for $5 \mathrm{~min}$. The reactive hyperhemia index $(\mathrm{RHI})$ represents the post-to-pre occlusion signal ratio on the occluded side normalized to the control side (24).

\section{- Arterial stiffness and central BP}

Pulse wave velocity (PWV) was assessed in the supine position (25). BP was measured just before PWV measurements with an Omron 750 IT BP device. Briefly, PWV was measured as the arterial distance divided by the transit time from the carotid to the femoral artery. The arterial distance was assessed from surface measurements subtracting the sternal notch femoral distance to the carotid-sternal notch distance. Transit time was automatically calculated from the foot of carotid and femoral pulses measured successively by applanation tonometry using R-wave of an ECG as a timing reference (Sphygmocor ${ }^{\circledR}$, Atcor Medical, Australia). Only measurements with a beat-to-beat transit time standard deviation below $5 \%$ were considered of good quality and used in the study. Using the same device, we also measured (i) central BP to calculate pulse pressure (systolic BP (SBP) - diastolic BP); and (ii) augmentation index (Alx).

\section{- Cardiac function and hemodynamic parameters}

Using applanation tonometry on the radial artery (Sphygmocor ${ }^{\circledR}$, Atcor Medical, Australia), myocardial perfusion was estimated by calculating the subendocardial viability ratio (Buckberg index: diastolic time index/tension-time index) $(26,27)$.

We measured with trans-thoracic bio-impedance cardiography (Task Force Monitor ${ }^{\circledR}$, CNSystems Medizintechnik, Austria) the following hemodynamic parameters: stroke volume, cardiac output, total peripheral resistance index, left ventricular ejection time, left ventricular work index and thoracic fluid content $(28,29)$.

\section{- Cardiovascular autonomic nervous system activity}

Finger arterial BP and heart rate (HR) were recorded continuously in the supine position for 6 min at a paced breathing rate of 12 breaths/min using photoplethysmographic sensors and synchronous 6-lead ECG recordings (Task force monitor ${ }^{\circledR}$, CNSystems Medizintechnik, Austria). Cardiac autonomic nervous system activity was assessed using spectral analysis of HR and SBP variations $(30,31)$. The opposite brachial artery was used to calibrate digital arterial BP measurements. Cardiac autonomic activity was expressed as normalized spectral HR variability: (i) normalized spectral index [i.e., the percentage of the highfrequency band (HF: $0.15-0.40 \mathrm{~Hz} /$ total spectrum) of HR variations (HFnu-RRI: vagal function); (ii) the ratio between low frequency (LF: $0.03-0.15 \mathrm{~Hz} /$ total spectrum) and HF bands of HR variations (LF/HF-RRI: sympatho-vagal balance) and (iii) LF band of the SBP spectrum (LF-SBP: $0.075-0.15$ Hz; vascular sympathetic activity).

\section{Statistical analyses}

Variables were expressed as mean \pm SD or as percentages. Comparisons between groups were performed for continuous variables by analysis of variance or the Mann-Whitney test as appropriate and by Chi-square test for comparisons of categorical variables. Quantitative variables were analyzed by different mixed models of ANOVA for longitudinal data including factor treatment (saxagliptin and placebo) and factor time with 2 levels when comparing changes between visits (i.e. V1 and V2) or three levels when analyzing the test meal response (0,60 and 120 min after breakfast). Interaction between the 2 factors was used to test possible effect of treatment on time-dependent changes in studied parameters. Normalizing transformations were made if necessary. All tests were two-sided at $5 \%$ significance level. Statistical analyses were performed with SAS version 9.4.

\section{Results}

\section{Patients' characteristics}

A total of 24 patients with IGT were included (Figure 2). We had to stop the investigations for one patient at Visit 2 because he complained of an atypical chest pain (we used his data only for Visit 1). The baseline characteristics are summarized in Table 1. Overall, patients had a mean body mass index of $36.8 \pm 4.8 \mathrm{~kg} / \mathrm{m}^{2}$, one third had hypertension, $4.2 \%$ had dyslipidemia, $8.3 \%$ a metabolic syndrome, and $8.3 \%$ had smoking habits. There was no significant difference for any clinical characteristic between saxagliptin and placebo groups.

\section{Glycemic parameters at Visit 1 and 2}

Table 2 shows that, at Visit 1 and 2, glucose values increased after breakfast in the placebo and saxagliptin groups (time effect: $p<0.0001)$, with a lower increase in the saxagliptin group ( $p<0.02$ for Visit $1, p<0.01$ for Visit 2) and an interaction time*treatment effect at Visit 1 and Visit 2 ( $p=0.0003$ and $p=0.009$, respectively). Three-month exposition to saxagliptin compared to placebo did not reduce FPG and HbA1c (Table 3).

\section{Body weight at Visit 1 and 2}

Patients had a slight loss in body weight between Visit 1 and 2 (time effect $p=0.007$ ), with no significant difference between treatment with placebo or saxagliptin (treatment effect: $p=0.153$ ) and no time*treatment interaction ( $p=0.171)$ (Table 3 ). Indeed, in the saxagliptin and placebo groups body weight was respectively $107.5 \pm 18.5$ and $97.2 \pm 14.5 \mathrm{~kg}$ at Visit 1 , and $106.1 \pm 20.2$ and $93.5 \pm 16.6 \mathrm{~kg}$ at Visit 2 .

\section{Endothelial and oxidative stress markers after standardized breakfast at Visit 1 and 2}


VCAM-1 decreased after breakfast at Visit 1 (time effect: $p<0.0001$ ) and at Visit 2 (time effect: $p<0.0001$ ), with no difference between placebo and saxagliptin groups. The same trends were found for E-selectin levels. Nitrotyrosin levels did not change post-prandially and did not differ at Visit 1 and 2 between placebo and saxagliptin groups (Table 2). The levels of these markers did not differ between Visit 1 and Visit 2 in the saxagliptin and placebo groups (Table 3 ).

\section{Microcirculatory cutaneous blood flow parameters at Visit 1 and 2}

Mean CBF at baseline (Visit 1 and Visit 2) and during paced breathing (Visit 1) increased after breakfast (time effect: $p<0.01$ at both visits), without any difference by experimental treatment. Microcirculatory endothelial function also changed after breakfast at Visit 1 and 2, with an increase of maximal CBF (time effect: $p<0.0001$ at both visits) and of CBF incremental area under the curve after Ach administration (time effect: $p<0.0001$ at both visits). These observations were similar in the saxagliptin and placebo groups (no treatment effect) (Table 4).

CBF at baseline, during paced breathing and after Ach did not differ at fasting between Visit 1 and Visit 2 in the saxagliptin and placebo groups (Table 3 ).

\section{Endothelial function at Visit 1 and 2}

Figure 3 (panel A and B) shows that endothelial function in small arteries (RHI) did not change after breakfast at Visit 1 and 2, whatever the subjects were in the placebo or the saxagliptin group.

RHI was similar at fasting during Visit 1 and Visit 2 in the saxagliptin and placebo groups (Table 3 ).

\section{Arterial stiffness and central pulse pressure at Visit 1 and 2}

Figure 3 (panel C to F) shows that PWV and central pulse pressure did not change after breakfast at Visit 1 and 2, whatever the subjects were in the placebo or saxagliptin group. At Visit 2, aortic Alx changed after breakfast (time effect: $\mathrm{p}=0.005$ ) without significant difference between groups (Figure $3 \mathrm{G}$ and $\mathrm{H}$ ).

There was no long-term effect of saxagliptin and placebo on arterial stiffness at fasting (Table 3).

\section{Cardiac function and hemodynamic parameters at Visit 1 and 2}

After breakfast, Buckberg index (Visit 1 and Visit 2), stroke volume (Visit 1) and left ventricular ejection time (Visit 1) decreased, whereas thoracic fluid content increased (Visit 1 and Visit 2). These changes after breakfast were similar in both groups (no treatment effect) (Table 5).

These parameters did not change between Visit 1 and Visit 2 (Table 3).

\section{Cardiovascular autonomic nervous system activity at Visit 1 and 2}

At Visit 1 and 2, HR increased after breakfast (time effect: $p<0.0001$ and 0.022 , respectively) with no significant time*treatment interaction. HFnu-RRI (vagal activity) was globally higher before and after breakfast in the saxagliptin group than in the placebo group (treatment effect: $p<0.004$ at Visit 1 and $p<0.05$ at Visit 2). HFnu-RRI decreased in both groups after breakfast (time effect: $p<0.0001$ and $<0.005$, respectively at Visit 1 and 2 ). At Visit 2, the decrease of HFnu$\mathrm{RRI}$ after breakfast was more sustained in the saxagliptin group than in the placebo group (interaction treatment*time effect $p=0.016$ ). At Visit 1, LF/HF-RRI (sympatho-vagal balance) was lower before and after breakfast in the saxagliptin group than in the placebo group (treatment effect: $p=0.047$ ), with an increase in both groups after breakfast (time effect: $p=0.022$ ). LF-SBP (vascular sympathetic activity) was similar in both groups at Visit 1 and 2 . LF-SBP changed after breakfast at Visit 1 (time effect: $p=0.042$ ) (Figure 4).

Values at fasting at Visit 1 (before saxagliptin was given) and Visit 2 were higher for HFnu-RRI ( $p=0.01$ ) and lower for LF/HF-RRI ( $p=0.031)$ in the saxagliptin group than in the placebo group without time*treatment interaction which means that these indexes did not change differently during long-term treatment (Table 3).

\section{Discussion}

In the present study, we have globally shown that, in individuals with IGT, saxagliptin as compared to placebo did not change any of the numerous hemodynamic and cardiac parameters we measured at fasting and after a standardized breakfast after three months of treatment. This was found despite a decrease of plasma glucose values after breakfast in the saxagliptin group which was significant by the first day of treatment and remained significant after three months of treatment. We only observed that the post-prandial decrease of vagal activity was more sustained in the saxagliptin group than in the placebo one. Altogether, our results show mostly neutral cardiovascular effect of this DPP4i at fasting and post-prandially.

To our knowledge, we were the first to investigate the effect of DPP4is on cardiac autonomic nervous system. Vagal depression and sympathetic predominance are common in obese patients and particularly in those with IGT (32-34) and may contribute to impair glucose metabolism and to hypertension $(35,36)$. Lifestyle changes including enhanced physical activity and weight loss were shown in the Diabetes Prevention Program to improve indexes of autonomic function in IGT individuals (37). In the current study we did not observe any change in parasympathetic and sympathetic activity between groups at fasting, but a more sustained post-prandial decrease in cardiac vagal activity after 12 weeks of treatment with saxagliptin than with placebo. Due to hazard and despite randomization, participants in the saxagliptin group had a higher vagal activity and a lower sympatho-vagal balance at inclusion than those in the placebo group and this difference hold the same after 12 weeks of treatment. This difference between groups need to interpret the results cautiously. Agents of DPP4i class increase moderately circulating GLP1 $(8,9)$ and insulin levels, which in turn might lower vagal activity and increase sympathetic activity $(3,38-$ 40). The depression of vagal activity in the saxagliptin group was unexpected since weight loss and lower post-prandial glucose levels might have contributed to improve vagal activity. Insulin response to the standard breakfast did not change after saxagliptin treatment (data not shown). Therefore such vagal 
depression might result from slight increase in GLP1 levels. Nevertheless such a trend towards a more marked post-prandial vagal depression in saxagliptintreated patients did not translate into changes of heart rate, blood pressure, artery stiffening, microcirculation flow or cardiac output responses to the standard meal.

We here found no detrimental effect of saxagliptin on myocardial function in our patients with IGT, when the Saxagliptin and Cardiovascular Outcomes in Patients with Type 2 Diabetes Mellitus study had found an increased risk of hospitalization for heart failure in patients who were at high cardiovascular risk $(18,19)$. We used trans-thoracic bio-impedance cardiography to measure hemodynamic parameters including stroke volume, cardiac output, left ventricular ejection time, left ventricular work index and thoracic fluid content. The validity of this method against several reference methods and its clinical utility were reported in heart failure patients (29). Neither at fasting nor post-prandially our data showed any significant difference for these parameters between saxagliptin and placebo treatment. Our reassuring data in people with an intermediate cardiovascular risk are in agreement with numerous preclinical studies (15). Furthermore, DPP4is have shown beneficial effects on different models of heart failure (41-44) and also in other studies which included patients with type 2 diabetes $(13,45)$. The risk of heart failure could be associated with saxagliptin per se and not all DPP4is $(12,15)$. Our results do not stand for this, in line with a pooled analysis of twenty phase 2 and 3 studies with saxagliptin which concluded that the drug use was neutral regarding heart failure (46).

DPP4is have been described to be neutral or beneficial on endothelial function (for review, 6). For example, preclinical studies showed that saxagliptin improved nitric oxide bioavailability in obese Zucker (47) and spontaneously hypertensive rats (17). In people with type 2 diabetes, treatment with DPP4i was associated with an improvement of flow-mediated dilatation (13) but this was not the case in other studies $(15,48)$. Both at fasting and post-prandially we studied endothelial function by two different methods, at microvascular level using Ach-induced vasodilatation and at small artery level by measuring reactive hyperhemia, and we measured VCAM-1 and E-selectin as endothelial markers. Endothelial function was shown to impair after glucose or fat load in relation with oxidative stress both in healthy individuals and in patients with type 2 diabetes (49). Such changes did not occur in our patients as we previously reported in patients with type 2 diabetes (22). The discrepancy with other studies might be due to the nature of the standardized breakfast we used, rich in carbohydrates similar to common French breakfast and including orange juice which may exert anti-oxidant effects (50,51). Moreover the data did not find any effect of saxagliptin on endothelial function or oxidative stress. Our neutral results in patients with IGT are concordant with those of BEGAMI study who investigated RHI in patients diagnosed with IGT or diabetes after an acute coronary syndrome (52).

Two studies had explored changes of PWV in patients with type 2 diabetes on sitagliptin treatment vs placebo (53) and on anagliptin vs glimepiride (54). In the first study, the changes in PWV after two years of treatment were similar in both groups (53). In the second one, PWV increased less during treatment with anagliptin than with glimepiride (54). Another study showed that alogliptin induces vascular relaxation (55). Our results are very consistent in favor of a neutrality of saxagliptin on a set of markers of arterial stiffness (PWV, Alx, central pulse pressures) measured at fasting and post-prandially in patients with IGT.

We report for the first time the effects of a DPP4i on microcirculation in individuals with IGT. As DPP4 enzyme is expressed both in the microvasculature and in the macrovascular bed (56), we could have expected saxagliptin-induced microcirculatory changes. This was not the case, neither at fasting nor during the post-prandial phase. On the contrary, linagliptin was recently reported to improve microvascular function in the fasting state in patients with type 2 diabetes, independently of glucose lowering (14).

This pilot study has strengths and limitations. The number of patients was relatively low but a large set of cardiovascular targets was explored both at fasting and in the post-prandial state after a standardized breakfast. Because we assessed this large number of endpoints, we may not exclude that the more sustained post-prandial vagal depression after breakfast in the saxagliptin group can be due to an inflated alpha error. The study was also strengthened by its randomized, placebo-controlled, double-blinded design. Furthermore, since several investigations explored the same vascular function (for example, PWV, Alx, central pulse pressures for arterial stiffness; $\mathrm{RHI}$, CBF after Ach, biological markers for endothelial function), the highly consistent results allow more reliable conclusions. Finally, our patients with IGT had no characterized cardiovascular abnormalities, which might account for the lack of improvement of cardiovascular function in the saxagliptin group.

Our detailed data about post-prandial cardiovascular changes are very rare. In patients with IGT, these changes appear to be highly reproducible when the same breakfast was given a second time 12 weeks later, as they were similar at Visit 1 and Visit 2 both in the saxagliptin and the placebo group. During the post-prandial phase, several significant changes occur:

- sympathetic activation and decrease in vagal activity as previously reported after oral glucose or a high carbohydrate meal, which probably results from insulin response while the role of GLP1 increase may not be excluded $(3,40,57,58)$;

- increase in CBF and in Ach-induced cutaneous vasodilatation as we recently observed in healthy individuals after the same standardized breakfast (unpublished) and in patients with type 2 diabetes (22), which are likely to result from endogenous insulin response to the meal;

- HR increase without significant changes in blood pressure, which probably results from sympathetic activation and vagal depression $(3,40)$;

- no change in arterial stiffness like in another study (59) whereas arterial stiffness was reported to decrease after a mixed meal in healthy individuals possibly due to meal-related increases in insulin or visceral vasodilation (60);

- decrease of subendocardial viability ratio (Buckberg index) which suggests a post-prandial reduction of myocardial perfusion similar to a previously reported post-prandial decrease in myocardial blood flow as evidenced by contrast echocardiography in type 2 diabetic patients (61). This decrease of myocardial blood flow is suggestive of microvascular myocardial impairment which might contribute to the reduction of left ventricle contractility as indicated in the current study by the decrease of stroke volume and the increase in thoracic fluid content. 


\section{Conclusion}

Our neutral cardiovascular results for saxagliptin in IGT patients fit well with the overall neutral cardiovascular effects observed for DPP4is in recent cardiovascular outcome trials carried out in patients with type 2 diabetes. Our data about myocardial function are also reassuring regarding a potential risk of heart failure observed in patients with type 2 diabetes treated with saxagliptin. Finally, we report very informative data about meal-induced cardiovascular changes in patients with IGT whose understanding requires further investigations.

\section{Abbreviations}

ACCES: "ACute and Chronic Effects of Saxagliptin"

Ach: acetylcholine

Alx: augmentation index

BP: blood pressure

CBF: cutaneous blood flow

DPP4i: dipeptidyl peptidase 4 inhibitor

FPG: fasting plasma glucose

GLP-1: Glucagon-like peptide 1

HF: high-frequency

HR: heart rate

IGT: impaired glucose tolerance

LF: low frequency

OGTT: oral glucose tolerance test

PWV: pulse wave velocity

$\mathrm{RHI}$ : reactive hyperhemia index

SBP: systolic blood pressure

UAER: urinary albumin excretion rate

VCAM-1: vascular cell adhesion molecule-1

\section{Declarations}

\section{Authors' contributions}

PV conceived the study. EC and PV designed the study protocol. AR and MF organized and performed the study investigations. AR, EC, SC, MF and PV supported the recruitment of the patients. EV managed statistical analyses. EC and AR wrote the first draft of the manuscript. All authors critically revised the manuscript for important intellectual content. They all read and approved the final manuscript.

\section{Acknowledgments}

The authors are grateful to Chantal Cyrille for her contribution as study nurse, Angela Sutton for biochemical measurements and Jean-Jacques Portal for statistical analyses.

\section{Funding source}

This research work was conducted with the financial supports from Assistance Publique- Hôpitaux de Paris and Bristol-Myers-Squibb and AstraZeneca companies. The companies agreed with the study design and encouraged the authors to submit this article for publication, but were not involved in the collection, analysis and interpretation of data.

\section{Availability of data and materials}

The datasets generated during and/or analysed during the current study are available from the corresponding author on reasonable request.

\section{Ethics approval and consent to participate}


The study protocol was approved by the local ethics committee (Comité de Protection des Personnes, Reference Number: JLD/AP-protocole 27-2011), and informed consent for the procedure was obtained from each participant.

\section{Consent for publication}

Not applicable

\section{Declaration of conflicting interests}

Amel Rezki, Marinos Fysekidis and Sabrina Chiheb declare they do not have any conflict of interest in relation with this manuscript.

Eric Vicaut declares counseling activities for Abbott, Boston, Genomichealth, Celgen, CEMKA, Bristol-Myers-Squibb, CreativPharmaceuticals, Genomic health, and having received research grants from Astra-Zeneca, Bristol-Myers-Squibb and Pfizer.

Emmanuel Cosson declares counseling activities for Abbott, AlphaDiab, Ascencia, Lilly, Medtronic, Merck-Sharp-Dohme, Novartis, Novo-Nordisk, Roche Diagnostics, Sanofi-Aventis, YpsoMed; having given lectures for Abbott, Astra-Zeneca, Bezins, Bristol-Myers-Squibb, LifeScan, Lilly, Merck-Sereno, Novartis, Novo-Nordisk, Roche Diagnostics, Sanofi-Aventis; and received research grants from Abbott, Air Liquide, Astra-Zeneca, Lilly, Novo-Nordisk, Roche diagnostics, Sanofi-Aventis, Ypsomed.

Paul Valensi declares having given lectures for Abbott, AstraZeneca, Bayer, Eli-Lilly, Hikma, Merck-Sharp-Dohme, Novo-Nordisk, Novartis, Pfizer, Sanofi, Servier ; received research grants from Abbott, Bristol-Myers-Squibb-AstraZeneca, Novo-Nordisk ; and participated to Expert Committees for Astra Zeneca, Boehringer Ingelheim, Merck-Serono, Novo-Nordisk, Daiichi-Sankyo, Sanofi, Servier.

\section{References}

1. Gregg EW, Li Y, Wang J, Rios Burrows N, Ali MK, Rolka D, et al. Changes in Diabetes-Related Complications in the United States, 1990-2010. N Engl J Med. 2014;370: 1514-23.

2. Ceriello A, Monnier L, Owens D. Glycaemic variability in diabetes: clinical and therapeutic implications. Lancet Diabetes Endocrinol. 2019;7:221-30.

3. Valensi P, Cosson E. Hemodynamic changes in postprandial state. Diabetes Metab. 2006;32:37-41.

4. DECODE Study Group, the European Diabetes Epidemiology Group. Decode Glucose tolerance and cardiovascular mortality: comparison of fasting and 2hour diagnostic criteria. Arch Intern Med. 2001;161:397-405

5. Valensi P, Prévost G. CVOTs: What did the endocrinologist learn ? Diabetes Res Clin Pract. 2020;159:107947.

6. Balakumar P, Dhanaraj SA. Cardiovascular pleiotropic actions of DPP-4 inhibitors: a step at the cutting edge in understanding their additional therapeutic potentials. Cell Signal. 2013;25:1799-803

7. Toth PP. Overview of saxagliptin efficacy and safety in patients with type 2 diabetes and cardiovascular disease or risk factors for cardiovascular disease. Vasc Health Risk Manag. 2014;11:9-23.

8. Thornberry NA, Gallwitz B. Mechanism of action of inhibitors of dipeptidyl-peptidase-4 (DPP-4). Best Pract Res Clin Endocrinol Metab. $2009 ; 23: 479-86$.

9. Drucker DJ, Nauck MA. The incretin system: glucagon-like peptide-1 receptor agonists and dipeptidyl peptidase-4 inhibitors in type 2 diabetes. Lancet. 2006; 368(9548):1696-705.

10. Scheen AJ. Cardiovascular effects of gliptins. Nat Rev Cardiol. 2013;10:73-84.

11. Avogaro A, Fadini GP. The effects of dipeptidyl peptidase-4 inhibition on microvascular diabetes complications. Diabetes Care. 2014;37:2884-94.

12. Xie W, Song X, Liu Z. Impact of dipeptidyl-peptidase 4 inhibitors on cardiovascular diseases. Vascul Pharmacol. 2018;109:17-26.

13. Leung M, Leung DY, Wong VW. Effects of dipeptidyl peptidase-4 inhibitors on cardiac and endothelial function in type 2 diabetes mellitus: A pilot study. Diab Vasc Dis Res. 2016;13:236-43.

14. Jax T, Stirban A, Terjung A, Esmaeili H, Berk A, Thiemann S, et al. A randomised, active- and placebo-controlled, three-period crossover trial to investigate short-term effects of the dipeptidyl peptidase-4 inhibitor linagliptin on macro- and microvascular endothelial function in type 2 diabetes. Cardiovasc Diabetol. 2017;16:13.

15. Pollack PS, Chadwick KD, Smith DM, Billger M, Hirshberg B, Iqbal N, Boulton DW. Nonclinical and clinical pharmacology evidence for cardiovascular safety of saxagliptin. Cardiovasc Diabetol. 2017;16:113.

16. Mistry GC, Maes AL, Lasseter KC, Davies MJ, Gottesdiener KM, Wagner JA, Herman

17. Effect of sitagliptin, a dipeptidyl peptidase-4 inhibitor, on blood pressure in nondiabetic patients with mild to moderate hypertension. $\mathrm{J}$ Clin Pharmacol 2008;48:592-8.

18. Mason RP, Jacob RF, Kubant R, Ciszewski A, Corbalan JJ, Malinski T. Dipeptidyl peptidase-4 inhibition with saxagliptin enhanced nitric oxide release and reduced blood pressure and sICAM-1 levels in hypertensive rats. Journal of Cardiovascular Pharmacology 60 (2012) 467-73.

19. Scirica BM, Bhatt DL, Braunwald E, et al. Saxagliptin and cardiovascular outcomes in patients with type 2 diabetes mellitus N Engl J Med 2013; 369:131726.

20. Scirica BM, Braunwald E, Raz I, et al. Heart failure, saxagliptin, and diabetes mellitus: observations from the SAVOR-TIMI 53 randomized trial. Circulation. 2015; 132: e198. 
21. Xia C, Goud A, D'Souza J, Dahagam C, Rao X, Rajagopalan S, Zhong J. DPP4 inhibitors and cardiovascular outcomes: safety on heart failure. Heart Fail Rev. 2017;22:299-304.

22. WHO: Definition, diagnosis and classification of diabetes mellitus and its complications: report of a WHO consultation. Part 1: diagnosis and classification of diabetes mellitus. Geneva, World Health Organization. 1999

23. Fysekidis M, Cosson E, Takbou K, Sutton A, Charnaux N, Banu I, Vicaut E, Valensi P. Effects of insulin analogs as an add-on to metformin on cutaneous microcirculation in type 2 diabetic patients. Microvasc Res 2018;116:6-14.

24. Valensi P, Smagghue O, Pariès J, Velayoudon P, Nguyen TN, Attali JR. Peripheral vasoconstrictor responses to sympathetic activation in diabetic patients: relationship with rheological disorders. Metabolism 1997;46:235-41.

25. Kang J, Kim HL, Seo JB, Lee JY, Moon MK, Chung WY. Endothelial function estimated by digital reactive hyperemia in patients with atherosclerotic risk factors or coronary artery disease. Heart Vessels 2018;33:706-12.

26. Chen Q, Chiheb S, Fysekidis M, Jaber Y, Brahimi M, Nguyen MT, et al. Arterial stiffness is elevated in normotensive type 2 diabetic patients with peripheral neuropathy. Nutr Metab Cardiovasc Dis. 2015;25:1041-9.

27. Crilly M, Coch C, Bruce M, Clark H, Williams D. Indices of cardiovascular function derived from peripheral pulse wave analysis using radial applanation tonometry: a measurement repeatability study. Vasc Med. 2007;12:189-97.

28. Chemla D, Nitenberg A, Teboul JL, Richard C, Monnet X, le Clesiau H, Valensi P, Brahimi M. Subendocardial viability ratio estimated by arterial tonometry: a critical evaluation in elderly hypertensive patients with increased aortic stiffness. Clin Exp Pharmacol Physiol 2008;35:909-15.

29. Wang X1, Sun HH, Van de Water JM. An advanced signal processing technique for impedance cardiography. EEE Trans Biomed Eng. 1995;42:224-30.

30. Albert NM, Hail MD, Li J, Young JB. Equivalence of the bioimpedance and thermodilution methods in measuring cardiac output in hospitalized patients with advanced, decompensated chronic heart failure. Am J Crit Care. 2004;13:469-79.

31. Bernardi L, Spallone V, Stevens M, Hilsted J, Frontoni S, Pop-Busui R, et al. Investigation methods for cardiac autonomic function in human research studies. Diabetes Metab Res Rev. 2011 27:654-64.

32. Brahimi M, Dabire H, Platon P, Hadj-Brahim F, Attali JR, Valensi P. Arterial rigidity and cardiovascular vagosympathetic activity in normotensive and hypertensive obese patients and type 2 diabetics. Arch Mal Coeur Vaiss 2001;94:944-6.

33. Valensi P, Thi BN, Lormeau B, Pariès J, Attali JR. Cardiac autonomic function in obese patients. Int J Obes Relat Metab Disord. 1995;19:113-8.

34. Laitinen T1, Lindström J, Eriksson J, Ilanne-Parikka P, Aunola S, Keinänen -Kiukaanniemi S, Tuomilehto J, Uusitupa M. Cardiovascular autonomic dysfunction is associated with central obesity in persons with impaired glucose tolerance. Diabet Med. 2011;28:699-704.

35. Chiheb S, Cosson E, Banu I, Hamo-Tchatchouang E, Cussac-Pillegand C, Nguyen MT, Valensi P. Are Obese Individuals with no Feature of Metabolic Syndrome but Increased Waist Circumference Really Healthy? A Cross Sectional Study. Exp Clin Endocrinol Diabetes. 2016;124:410-6.

36. Ayad F, Belhadj M, Pariés J, Attali JR, Valensi P. Association between cardiac autonomic neuropathy and hypertension and its potential influence on diabetic complications. Diabet Med. 2010;27:804-11.

37. Banu I, Nguyen MT, Hamo-Tchatchouang E, Cosson E, Valensi P. Relationship between blood pressure, heart rate and cardiac autonomic dysfunction in non-diabetic obese patients. Ann Cardiol Angeiol (Paris). 2015;64:139-44.

38. Carnethon MR, Prineas RJ, Temprosa M, Zhang ZM, Uwaifo G, Molitch ME; Diabetes Prevention Program Research Group. The association among autonomic nervous system function, incident diabetes, and intervention arm in the Diabetes Prevention Program. Diabetes Care 2006;29:914-9.

39. Bharucha AE, Charkoudian N, Andrews CN, Camilleri M, Sletten D, Zinsmeister AR, Low PA. Effects of glucagon-like peptide-1, yohimbine, and nitrergic modulation on sympathetic and parasympathetic activity in humans. Am J Physiol Regul Integr Comp Physiol. 2008; 295:R874-R880.

40. Berkelaar M, Eekhoff EM, Simonis-Bik AM, et al. Effects of induced hyperinsulinaemia with and without hyperglycaemia on measures of cardiac vagal control. Diabetologia. 2013;56:1436-43.

41. Valensi P, Chiheb S, Fysekidis M. Insulin- and glucagon-like peptide-1-induced changes in heart rate and vagosympathetic activity: why they matter. Diabetologia. 2013;56:1196-200.

42. Anderluh M, Kocic G, Tomovic K, Kocic R, Deljanin-llic M, Smelcerovic A. Cross-talk between the dipeptidyl peptidase-4 and stromal cell-derived factor-1 in stem cell homing and myocardial repair: Potential impact of dipeptidyl peptidase-4 inhibitors. Pharmacol Ther. 2016;167:100-7.

43. Aoyama M, Kawase H, Bando YK, Monji A, Murohara T. Dipeptidyl Peptidase 4 Inhibition Alleviates Shortage of Circulating Glucagon-Like Peptide-1 in Heart Failure and Mitigates Myocardial Remodeling and Apoptosis via the Exchange Protein Directly Activated by Cyclic AMP 1/Ras-Related Protein 1 Axis. Circ Heart Fail. 2016;9:e002081.

44. Wei SG, Zhang ZH, Yu Y, Weiss RM, Felder RB. Central actions of the chemokine stromal cell-derived factor 1 contribute to neurohumoral excitation in heart failure rats. Hypertension. 2012;59:991-8.

45. Vila Petroff MG, Egan JM, Wang X, Sollott SJ. Glucagon-like peptide-1 increases cAMP but fails to augment contraction in adult rat cardiac myocytes. Circ Res. 2001;89:445-52.

46. Fujiwara T, Yoshida M, Nakamura T, et al. Dipeptidyl peptidase-4 inhibitors are associated with improved left ventricular diastolic function after acute myocardial infarction in diabetic patients. Heart Vessels. 2015;30:696-701.

47. Iqbal N, Parker A, Frederich R, Donovan M, Hirshberg B. Assessment of the cardiovascular safety of saxagliptin in patients with type 2 diabetes mellitus: pooled analysis of 20 clinical trials. Cardiovasc Diabetol. 2014;13:33.

48. Mason RP, Jacob RF, Kubant R, et al. Effect of enhanced glycemic control with saxagliptin on endothelial nitric oxide release and CD40 levels in obese rats. J Atheroscler Thromb. 2011;18:774-83. 
49. Tripolt NJ, Aberer F, Riedl R, Url J, Dimsity G, Meinitzer A, et al. Effects of linagliptin on endothelial function and postprandial lipids in coronary artery disease patients with early diabetes: a randomized, placebo-controlled, double-blind trial. Cardiovasc Diabetol. 2018;17:71.

50. Ceriello A, Taboga C, Tonutti L, Quagliaro L, Piconi L, Bais B, et al. Evidence for an independent and cumulative effect of postprandial hypertriglyceridemia and hyperglycemia on endothelial dysfunction and oxidative stress generation: effects of short- and long-term simvastatin treatment. Circulation 2002;106:1211-8.

51. Sanchez-Moreno C, Cano MP, de Ancos B, Plaza L, Olmedilla B, Granado F, Martin A: Effect of orange juice intake on vitamin C concentrations and biomarkers of antioxidant status in humans. Am J Clin Nutr 2003;78:454-60.

52. Buscemi S, Rosafio G, Arcoleo G, Mattina A, Canino B, Montana M, Verga S, Rini G: Effects of red orange juice intake on endothelial function and inflammatory markers in adult subjects with increased cardiovascular risk. Am J Clin Nutr 2012;95:1089-95.

53. Hage C, Brismar K, Lundman P, Norhammar A, Rydén L, Mellbin L. The DPP-4 inhibitor sitagliptin and endothelial function in patients with acute coronary syndromes and newly detected glucose perturbations: a report from the BEGAMI study. Diab Vasc Dis Res. 2014;11:290-3.

54. Tomiyama H, Miwa T, Kan K, et al. Impact of glycemic control with sitagliptin on the 2-year progression of arterial stiffness: a sub-analysis of the PROLOGUE study. Cardiovasc Diabetol. 2016;15:150.

55. Tahara N, Yamagishi SI, Bekki M, et al. Anagliptin, A Dipeptidyl Peptidase-4 Inhibitor Ameliorates Arterial Stiffness in Association with Reduction of Remnant-Like Particle Cholesterol and Alanine Transaminase Levels in Type 2 Diabetic Patients. Curr Vasc Pharmacol. 2016;14:552-62.

56. Shah Z, Pineda C, Kampfrath T, Maiseyeu A, Ying Z, Racoma I, et al. Acute DPP-4 inhibition modulates vascular tone through GLP-1 independent pathways. Vascul Pharmacol 2011;55:2-9.

57. Matheeussen V, Baerts L, De Meyer G, De Keulenaer G, Van der Veken P, Augustyns K, et al. Expression and spatial heterogeneity of dipeptidyl peptidases in endothelial cells of conduct vessels and capillaries. Biol Chem. 2011;392:189-98.

58. Tentolouris N, Tsigos C, Perea D, Koukou E, Kyriaki D, Kitsou E, et al. Differential effects of high-fat and high-carbohydrate isoenergetic meals on cardiac autonomic nervous system activity in lean and obese women. Metabolism. 2003;52:1426-32.

59. Scott EM, Greenwood JP, Vacca G, Stoker JB, Gilbey SG, Mary DA. Carbohydrate ingestion, with transient endogenous insulinaemia, produces both sympathetic activation and vasodilatation in normal humans. Clin Sci (Lond). 2002;102:523-9.

60. Phillips LK, Peake JM, Zhang X, Hickman IJ, Kolade O, Sacre JW, et al. The effect of a high-fat meal on postprandial arterial stiffness in men with obesity and type 2 diabetes. J Clin Endocrinol Metab. 2010;95:4455-9

61. Taylor JL, Curry TB, Matzek LJ, Joyner MJ, Casey DP. Acute effects of a mixed meal on arterial stiffness and central hemodynamics in healthy adults. Am J Hypertens. 2014;27:331-7.

62. Scognamiglio R, Negut C, De Kreutzenberg SV, Tiengo A, Avogaro A. Postprandial myocardial perfusion in healthy subjects and in type 2 diabetic patients. Circulation. 2005;112:179-84.

\section{Tables}

Table 1: Patients characteristics at inclusion

\begin{tabular}{|llll|}
\hline & Placebo $(\mathrm{n}=\mathbf{1 2})$ & Saxagliptin $(\mathrm{n}=\mathbf{1 2})$ & Total $(\mathrm{n}=\mathbf{2 4})$ \\
\hline Age (years) & $49.8 \pm 14.6$ & $40.0 \pm 10.7$ & $44.9 \pm 13.5$ \\
\hline Female gender (\%) & $9(75.0)$ & $10(83.3)$ & $19(79.2)$ \\
\hline Body mass index $\left(\mathrm{kg} / \mathrm{m}^{2}\right)$ & $36.2 \pm 5.6$ & $37.4 \pm 4.1$ & $36.8 \pm 4.9$ \\
\hline Waist circumference (cm) & $108.1 \pm 9.1$ & $114.3 \pm 13.4$ & $111.2 \pm 11.7$ \\
\hline Systolic Blood Pressure (mmHg) & $125.6 \pm 14.6$ & $120.6 \pm 11.0$ & $123.1 \pm 12.9$ \\
\hline Diastolic Blood Pressure (mmHg) & $75.3 \pm 9.3$ & $74.0 \pm 7.1$ & $74.6 \pm 8.1$ \\
\hline Hypertension (\%) & $3(25)$ & $5(41.7)$ & $8(33.3)$ \\
\hline Dyslipidemia (\%) & $1(8.3)$ & $0(0)$ & $1(4.2)$ \\
\hline Smokers (\%) & $2(16.7)$ & $0(0)$ & $2(8.3)$ \\
\hline Obstructive sleep apnea syndrome (\%) & $1(8.3)$ & $1(8.3)$ & $2(8.3)$ \\
\hline
\end{tabular}

Data are mean \pm SD or $\mathrm{n}(\%)$

Table 2: Biological measurements at fasting and after breakfast during Visit 1 and Visit 2 


\begin{tabular}{|c|c|c|c|c|c|c|c|c|c|c|c|}
\hline & & \multicolumn{2}{|l|}{ Visit 1} & \multicolumn{3}{|c|}{ p values (Visit 1) } & \multicolumn{2}{|l|}{ Visit 2} & \multicolumn{3}{|c|}{ p values (Visit 2) } \\
\hline & & Placebo & Saxagliptin & $\begin{array}{l}\text { Treatment } \\
\text { effect }\end{array}$ & $\begin{array}{l}\text { Time } \\
\text { effect }\end{array}$ & Interaction & Placebo & Saxagliptin & $\begin{array}{l}\text { Treatment } \\
\text { effect }\end{array}$ & $\begin{array}{l}\text { Time } \\
\text { effect }\end{array}$ & Interact \\
\hline \multicolumn{12}{|l|}{ Metabolism } \\
\hline \multirow[t]{4}{*}{$\begin{array}{l}\text { Plasma glucose } \\
\text { (mmol/l) }\end{array}$} & T 0 & $\begin{array}{l}5.5 \pm \\
0.7\end{array}$ & $5.5 \pm 0.8$ & $<0.02$ & $<0.001$ & $p=0.0003$ & $\begin{array}{l}5.6 \pm \\
0.8\end{array}$ & $5.8 \pm 0.7$ & $p<0.01$ & $p<0.001$ & $p=0.00 \mathrm{c}$ \\
\hline & T 60 & $\begin{array}{l}8.5 \pm \\
1.3\end{array}$ & $6.9 \pm 0.9$ & & & & $\begin{array}{l}9.4 \pm \\
1.4\end{array}$ & $8.0 \pm 1.8$ & & & \\
\hline & $\begin{array}{l}\mathrm{T} \\
120\end{array}$ & $\begin{array}{l}7.4 \pm \\
1.0\end{array}$ & $6.2 \pm 1.0$ & & & & $\begin{array}{l}8.0 \pm \\
0.3\end{array}$ & $6.6 \pm 1.3$ & & & \\
\hline & T180 & $\begin{array}{l}5.7 \pm \\
0.6\end{array}$ & $6.0 \pm 1.6$ & & & & $\begin{array}{l}6.4 \pm \\
1.0\end{array}$ & $6.4 \pm 1.2$ & & & \\
\hline HbA1c (\%) & T 0 & $\begin{array}{l}5.6 \pm \\
0.3\end{array}$ & $5.7 \pm 0.5$ & 0.709 & & & $\begin{array}{l}5.6 \pm \\
0.4\end{array}$ & $5.7 \pm 0.4$ & 0.690 & & \\
\hline $\begin{array}{l}\mathrm{HbA1c} \\
(\mathrm{mmol} / \mathrm{mol})\end{array}$ & T 0 & $38 \pm 2.6$ & $39 \pm 3.5$ & 0.709 & & & $38 \pm 2.7$ & $39 \pm 2.8$ & 0.690 & & \\
\hline \multicolumn{12}{|l|}{ Endothelial markers } \\
\hline \multirow[t]{2}{*}{ VCAM-1 (ng/ml) } & T 0 & $\begin{array}{l}594 \pm \\
158\end{array}$ & $621 \pm 90$ & 0.489 & 0.0001 & 0.445 & $\begin{array}{l}578 \pm \\
142\end{array}$ & $609 \pm 103$ & 0.431 & 0.0001 & 0.576 \\
\hline & $\begin{array}{l}\mathrm{T} \\
120\end{array}$ & $\begin{array}{l}516 \pm \\
137\end{array}$ & $574 \pm 78$ & & & & $\begin{array}{l}513 \pm \\
113\end{array}$ & $560 \pm 74$ & & & \\
\hline \multirow[t]{2}{*}{ E Selectin (ng/ml) } & T 0 & $36 \pm 15$ & $40 \pm 20$ & 0.503 & 0.052 & 0.315 & $36 \pm 15$ & $40 \pm 20$ & 0.531 & 0.058 & 0.703 \\
\hline & $\begin{array}{l}\mathrm{T} \\
120\end{array}$ & $35 \pm 11$ & $39 \pm 20$ & & & & $36 \pm 14$ & $38 \pm 20$ & & & \\
\hline UAER (mg/24h) & T 0 & $6 \pm 3$ & $18 \pm 26$ & 0.164 & & & $5 \pm 4$ & $18 \pm 19$ & 0.116 & & \\
\hline \multicolumn{12}{|c|}{ Marker of oxidative stress } \\
\hline \multirow[t]{2}{*}{$\begin{array}{l}\text { Nitrotyrosin } \\
\text { (nmol/L) }\end{array}$} & TO & $91 \pm 37$ & $87 \pm 30$ & 0.207 & 0.322 & 0.156 & $\begin{array}{l}128 \pm \\
58\end{array}$ & $95 \pm 37$ & 0.692 & 0.680 & 0.140 \\
\hline & $\begin{array}{l}\mathrm{T} \\
120\end{array}$ & $\begin{array}{l}120 \pm \\
69\end{array}$ & $82 \pm 25$ & & & & $\begin{array}{l}107 \pm \\
47\end{array}$ & $126 \pm 100$ & & & \\
\hline
\end{tabular}

Data are mean $\pm S D$.

T0: Fasting; T60 and T120: 60 and 120 min after breakfast; VCAM-1: Vascular cell adhesion molecule-1; UAER: urinary albumin excretion rate Time effect: repeated measures ANOVA from T0 to T120. Visit 1: placebo or saxagliptin was given before breakfast (acute effect); Visit 2: placebo or saxagliptin had been given for 3 months (long-term effect).

Table 3: Comparisons of metabolic, endothelial and oxidative stress markers and cardiovascular parameters between Visit 1 and Visit 2 at fasting (long-term effects of saxagliptin on measurements performed at fasting). The table shows $p$ values. 


\begin{tabular}{|c|c|c|c|}
\hline & Treatment effect & Time effect & Interaction \\
\hline Body weight & 0.153 & 0.007 & 0.171 \\
\hline \multicolumn{4}{|l|}{ Metabolic markers } \\
\hline Plasma glucose & 0.522 & 0.076 & 0.722 \\
\hline $\mathrm{HbA1c}$ & 0.746 & 0.778 & 0.872 \\
\hline \multicolumn{4}{|l|}{ Endothelial markers } \\
\hline Vascular Cellular Adhesion Molecule-1 & 0.522 & 0.076 & 0.722 \\
\hline E selectin & 0.661 & 0.893 & 0.481 \\
\hline Urinary albumin excretion rate & 0.590 & 0.623 & 0.391 \\
\hline \multicolumn{4}{|l|}{ Marker of oxidative stress } \\
\hline Nitrotyrosin & 0.749 & 0.778 & 0.872 \\
\hline \multicolumn{4}{|c|}{ Microcirculatory cutaneous blood flow measurement } \\
\hline CBF at baseline & 0.255 & 0.401 & 0.062 \\
\hline CBF during paced breathing & 0.931 & 0.06 & 0.376 \\
\hline Maximum CBF after Ach & 0.282 & 0.969 & 0.952 \\
\hline Time to peak CBF after Ach & 0.364 & 0.947 & 0.222 \\
\hline Incremental AUC CBF after Ach & 0.262 & 0.887 & 0.855 \\
\hline \multicolumn{4}{|l|}{ Digital endothelial function } \\
\hline Reactive Hyperhemia index & 0.784 & 0.630 & 0.015 \\
\hline \multicolumn{4}{|l|}{ Arterial stiffness and central pulse pressure } \\
\hline Pulse wave velocity & 0.680 & 0.199 & 0.779 \\
\hline Central pulse pressure & 0.993 & 0.274 & 0.634 \\
\hline Augmentation index & 0.825 & 0.093 & 0.059 \\
\hline \multicolumn{4}{|c|}{ Cardiac function and hemodynamic parameters } \\
\hline Heart rate & 0.670 & 0.907 & 0.624 \\
\hline Buckberg index & 0.912 & 0.088 & 0.126 \\
\hline Stroke volume & 0.387 & 0.682 & 0.427 \\
\hline Cardiac output & 0.218 & 0.466 & 0.800 \\
\hline Total peripheral resistance & 0.061 & 0.914 & 0.876 \\
\hline Left ventricular ejection time & 0.574 & 0.704 & 0.833 \\
\hline Left ventricular work index & 0.777 & 0.712 & 0.576 \\
\hline Thoracic fluid content & 0.614 & 0.437 & 0.882 \\
\hline \multicolumn{4}{|l|}{ Cardiovascular autonomic nervous activity } \\
\hline HFnu-RRI & 0.010 & 0.509 & 0.712 \\
\hline LF/HF-RRI & 0.031 & 0.523 & 0.541 \\
\hline LF-SBP & 0.770 & 0.164 & 0.126 \\
\hline
\end{tabular}

Ach: acetylcholine; AUC: incremental area under the curve 3 min after Ach administration; CBF: cutaneous blood flow; HFnu-RRI: vagal function; LF/HF-RRI: sympatho-

vagal balance; LF-SBP: vascular sympathetic activity

Table 4: Microcirculatory cutaneous blood flow measurement at fasting and after breakfast during Visit 1 and Visit 2 


\begin{tabular}{|c|c|c|c|c|c|c|c|c|c|c|c|c|}
\hline & & & \multicolumn{2}{|l|}{ Visit 1} & \multicolumn{3}{|l|}{$\mathbf{P}$} & \multicolumn{2}{|l|}{ Visit 2} & \multicolumn{3}{|l|}{$\mathbf{P}$} \\
\hline & & & Placebo & Saxagliptin & $\begin{array}{l}\text { Treatment } \\
\text { effect }\end{array}$ & $\begin{array}{l}\text { Time } \\
\text { effect }\end{array}$ & Interaction & Placebo & Saxagliptin & $\begin{array}{l}\text { Treatment } \\
\text { effect }\end{array}$ & $\begin{array}{l}\text { Time } \\
\text { Effect }\end{array}$ & II \\
\hline \multirow[t]{3}{*}{ At baseline } & \multirow[t]{3}{*}{ CBF (PU) } & T 0 & $\begin{array}{l}5.9 \pm \\
3.1\end{array}$ & $4.7 \pm 2.0$ & 0.639 & 0.0009 & 0.603 & $\begin{array}{l}4.1 \pm \\
1.0\end{array}$ & $8.8 \pm 9.3$ & 0.555 & 0.005 & 0 \\
\hline & & $\begin{array}{l}T \\
60\end{array}$ & $\begin{array}{l}11.0 \pm \\
5.3\end{array}$ & $9.0 \pm 7.9$ & & & & $\begin{array}{l}12.8 \pm \\
10.1\end{array}$ & $13.0 \pm 13.8$ & & & \\
\hline & & $\begin{array}{l}\mathrm{T} \\
120\end{array}$ & $\begin{array}{l}9.9 \pm \\
4.7\end{array}$ & $10.6 \pm 9.8$ & & & & $\begin{array}{l}10.4 \pm \\
6.0\end{array}$ & $11.0 \pm 6.7$ & & & \\
\hline \multirow[t]{3}{*}{$\begin{array}{l}\text { During paced } \\
\text { breathing }\end{array}$} & \multirow[t]{3}{*}{$\begin{array}{l}\text { CBF (\% } \\
\text { change) }\end{array}$} & T 0 & $\begin{array}{l}16.2 \pm \\
5.7\end{array}$ & $14.7 \pm 5.5$ & 0.646 & 0.0004 & 0.437 & $\begin{array}{l}18.4 \pm \\
4.8\end{array}$ & $19.9 \pm 6.7$ & 0.393 & 0.405 & 0 \\
\hline & & $\begin{array}{l}T \\
60\end{array}$ & $\begin{array}{l}18.7 \pm \\
6.4\end{array}$ & $19.3 \pm 4.5$ & & & & $\begin{array}{l}17.7 \pm \\
4.7\end{array}$ & $19.8 \pm 5.0$ & & & \\
\hline & & $\begin{array}{l}\mathrm{T} \\
120\end{array}$ & $\begin{array}{l}20.3 \pm \\
5.6\end{array}$ & $18.7 \pm 4.7$ & & & & $\begin{array}{l}17.3 \pm \\
4.8\end{array}$ & $18.0 \pm 3.7$ & & & \\
\hline \multirow[t]{9}{*}{$\begin{array}{l}\text { After Ach } \\
\text { administration }\end{array}$} & \multirow[t]{3}{*}{$\begin{array}{l}\operatorname{Max} C B F \\
(P U)\end{array}$} & T 0 & $\begin{array}{l}36.5 \pm \\
28.3\end{array}$ & $44.4 \pm 15.5$ & 0.273 & 0.0001 & 0.508 & $\begin{array}{l}37.9 \pm \\
23.2\end{array}$ & $44.7 \pm 25.9$ & 0.637 & 0.0001 & 0 \\
\hline & & $\begin{array}{l}T \\
60\end{array}$ & $\begin{array}{l}67.5 \pm \\
36.1\end{array}$ & $88.2 \pm 35.2$ & & & & $\begin{array}{l}89.8 \pm \\
45.3\end{array}$ & $73.7 \pm 28.7$ & & & \\
\hline & & $\begin{array}{l}\mathrm{T} \\
120\end{array}$ & $\begin{array}{l}76.3 \pm \\
36.5\end{array}$ & $83.4 \pm 30.0$ & & & & $\begin{array}{l}94.4 \pm \\
44.2\end{array}$ & $77.3 \pm 28.9$ & & & \\
\hline & \multirow[t]{3}{*}{$\begin{array}{l}\text { Time to } \\
\text { peak (sec) }\end{array}$} & T 0 & $\begin{array}{l}137.0 \pm \\
195.0\end{array}$ & $\begin{array}{l}109.4 \pm \\
38.9\end{array}$ & 0.455 & 0.620 & 0.364 & $\begin{array}{l}97.7 \pm \\
50.1\end{array}$ & $\begin{array}{l}104.7 \pm \\
28.6\end{array}$ & 0.784 & 0.217 & 0 \\
\hline & & $\begin{array}{l}T \\
60\end{array}$ & $\begin{array}{l}93.2 \pm \\
27.5\end{array}$ & $\begin{array}{l}124.8 \pm \\
32.3\end{array}$ & & & & $\begin{array}{l}117.6 \pm \\
38.3\end{array}$ & $\begin{array}{l}113.1 \pm \\
42.6\end{array}$ & & & \\
\hline & & $\begin{array}{l}\mathrm{T} \\
120\end{array}$ & $\begin{array}{l}175.1 \pm \\
190.6\end{array}$ & $\begin{array}{l}109.5 \pm \\
29.7\end{array}$ & & & & $\begin{array}{l}118.2 \pm \\
43.1\end{array}$ & $\begin{array}{l}106.3 \pm \\
45.5\end{array}$ & & & \\
\hline & \multirow{3}{*}{$\begin{array}{l}\text { Incremental } \\
\text { AUC of CBF } \\
\text { (PU/sec) }\end{array}$} & T 0 & $\begin{array}{l}5176 \pm \\
3734\end{array}$ & $\begin{array}{l}8733 \pm \\
5296\end{array}$ & 0.650 & 0.0001 & 0.859 & $\begin{array}{l}15224 \\
\pm 7915\end{array}$ & $\begin{array}{l}7122 \pm \\
5892\end{array}$ & 0.459 & 0.0001 & 0 \\
\hline & & $\begin{array}{l}T \\
60\end{array}$ & $\begin{array}{l}13762 \\
\pm 8414\end{array}$ & $\begin{array}{l}16557 \pm \\
8784\end{array}$ & & & & $\begin{array}{l}23432 \pm \\
21723\end{array}$ & $\begin{array}{l}16585 \pm \\
7326\end{array}$ & & & \\
\hline & & $\begin{array}{l}\mathrm{T} \\
120\end{array}$ & $\begin{array}{l}16305 \\
\pm \\
10864\end{array}$ & $\begin{array}{l}17743 \pm \\
9443\end{array}$ & & & & $\begin{array}{l}23371 \\
\pm \\
19030\end{array}$ & $\begin{array}{l}6102 \pm \\
6805\end{array}$ & & & \\
\hline
\end{tabular}

Data are mean \pm SD.

Ach: acetycholine; AUC: incremental area under the curve during 3 min after Ach administration; CBF: cutaneous blood flow; PU: perfusion units; T0: Fasting, T60 and T120: 60 and 120 min after breakfast.

Time effect: repeated measures ANOVA from T0 to T120.

Visit 1: placebo or saxagliptin were given before breakfast (acute effect); Visit 2: placebo or saxagliptin had been given for 3 months (long-term effect).

Table 5: Cardiac function and hemodynamic parameters at fasting and after breakfast during Visit 1 and Visit 2 


\begin{tabular}{|c|c|c|c|c|c|c|c|c|c|c|c|}
\hline & & \multicolumn{2}{|l|}{ Visit 1} & \multicolumn{3}{|l|}{$P$} & \multicolumn{2}{|l|}{ Visit 2} & \multicolumn{3}{|l|}{$\mathbf{P}$} \\
\hline & & Placebo & Saxagliptin & $\begin{array}{l}\text { Treatment } \\
\text { effect }\end{array}$ & $\begin{array}{l}\text { Time } \\
\text { effect }\end{array}$ & Interaction & Placebo & Saxagliptin & $\begin{array}{l}\text { Treatment } \\
\text { effect }\end{array}$ & $\begin{array}{l}\text { Time } \\
\text { Effect }\end{array}$ & Interaction \\
\hline \multirow[t]{3}{*}{$\begin{array}{l}\text { Buckberg index } \\
(\%)\end{array}$} & TO & $\begin{array}{l}155.5 \pm \\
26.8\end{array}$ & $\begin{array}{l}163.3 \pm \\
18.3\end{array}$ & 0.816 & 0.004 & 0.485 & $\begin{array}{l}156.4 \pm \\
29.5\end{array}$ & $\begin{array}{l}152.3 \pm \\
24.0\end{array}$ & 0.767 & 0.047 & 0.774 \\
\hline & $\begin{array}{l}T \\
60\end{array}$ & $\begin{array}{l}152.5 \pm \\
29.5\end{array}$ & $\begin{array}{l}151.0 \pm \\
18.8\end{array}$ & & & & $\begin{array}{l}151.0 \pm \\
24.2\end{array}$ & $\begin{array}{l}146.2 \pm \\
23.0\end{array}$ & & & \\
\hline & $\begin{array}{l}\mathrm{T} \\
120\end{array}$ & $\begin{array}{l}146.8 \pm \\
24.7\end{array}$ & $\begin{array}{l}149.0 \pm \\
18.3\end{array}$ & & & & $\begin{array}{l}146.3 \pm \\
24.9\end{array}$ & $\begin{array}{l}142.8 \pm \\
15.1\end{array}$ & & & \\
\hline \multirow{3}{*}{$\begin{array}{l}\text { Stroke volume } \\
\text { (ml) }\end{array}$} & TO & $64 \pm 19$ & $77 \pm 14$ & 0.087 & 0.009 & 0.620 & $69 \pm 25$ & $74 \pm 16$ & 0.487 & 0.065 & 0.905 \\
\hline & $\begin{array}{l}T \\
60\end{array}$ & $61 \pm 14$ & $71 \pm 11$ & & & & $65 \pm 18$ & $71 \pm 15$ & & & \\
\hline & $\begin{array}{l}\mathrm{T} \\
120\end{array}$ & $60 \pm 13$ & $70 \pm 10$ & & & & $67 \pm 16$ & $71 \pm 14$ & & & \\
\hline \multirow[t]{3}{*}{$\begin{array}{l}\text { Cardiac output } \\
\text { (l/min) }\end{array}$} & TO & $4.5 \pm 1.3$ & $5.5 \pm 1.1$ & 0.103 & 0.147 & 0.197 & $\begin{array}{l}4.7 \pm \\
1.5\end{array}$ & $5.3 \pm 1.0$ & 0.351 & 0.127 & 0.461 \\
\hline & $\begin{array}{l}T \\
60\end{array}$ & $4.5 \pm 1.2$ & $5.1 \pm 0.8$ & & & & $\begin{array}{l}4.6 \pm \\
1.2\end{array}$ & $5.1 \pm 1.1$ & & & \\
\hline & $\begin{array}{l}\mathrm{T} \\
120\end{array}$ & $4.5 \pm 1.2$ & $5.3 \pm 0.7$ & & & & $4.9 \pm 1.3$ & $5.3 \pm 0.9$ & & & \\
\hline \multirow{3}{*}{$\begin{array}{l}\text { Total peripheral } \\
\text { resistance } \\
\left(\text { dyne* }{ }^{\star} \mathrm{m}^{2} / \mathrm{cm}^{\wedge} 5 \text { ) }\right.\end{array}$} & TO & $3164 \pm 558$ & $2643 \pm 540$ & 0.179 & 0.368 & 0.204 & $\begin{array}{l}3160 \pm \\
690\end{array}$ & $2724 \pm 653$ & 0.431 & 0.862 & 0.375 \\
\hline & $\begin{array}{l}T \\
60\end{array}$ & $3206 \pm 731$ & $2908 \pm 432$ & & & & $\begin{array}{l}3063 \pm \\
886\end{array}$ & $2908 \pm 675$ & & & \\
\hline & $\begin{array}{l}\mathrm{T} \\
120\end{array}$ & $3048 \pm 683$ & $2915 \pm 598$ & & & & $\begin{array}{l}2960 \pm \\
928\end{array}$ & $2871 \pm 736$ & & & \\
\hline \multirow{3}{*}{$\begin{array}{l}\text { Left ventricular } \\
\text { ejection time (ms) }\end{array}$} & TO & $302 \pm 24$ & $300 \pm 20$ & 0.969 & 0.001 & 0.368 & $305 \pm 22$ & $298 \pm 21$ & 0.771 & 0.062 & 0.356 \\
\hline & $\begin{array}{l}T \\
60\end{array}$ & $296 \pm 20$ & $300 \pm 17$ & & & & $300 \pm 16$ & $297 \pm 18$ & & & \\
\hline & $\begin{array}{l}\mathrm{T} \\
120\end{array}$ & $291 \pm 20$ & $291 \pm 19$ & & & & $298 \pm 18$ & $294 \pm 24$ & & & \\
\hline \multirow{3}{*}{$\begin{array}{l}\text { Left ventricular } \\
\text { work index } \\
\left(\mathrm{mmHg} / \mathrm{min} / \mathrm{m}^{2}\right)\end{array}$} & TO & $2.7 \pm 0.8$ & $2.9 \pm 0.7$ & 0.561 & 0.642 & 0.852 & $2.9 \pm 0.8$ & $2.8 \pm 0.4$ & 0.605 & 0.035 & 0.754 \\
\hline & $\begin{array}{l}T \\
60\end{array}$ & $2.7 \pm 0.6$ & $2.8 \pm 0.4$ & & & & $2.7 \pm 0.5$ & $2.7 \pm 0.6$ & & & \\
\hline & $\begin{array}{l}\mathrm{T} \\
120\end{array}$ & $2.7 \pm 0.6$ & $2.9 \pm 0.4$ & & & & $3.0 \pm 0.5$ & $2.8 \pm 0.5$ & & & \\
\hline \multirow{3}{*}{$\begin{array}{l}\text { Thoracic fluid } \\
\text { content (1/kOhm) }\end{array}$} & TO & $24 \pm 3$ & $23 \pm 4$ & 0.369 & 0.001 & 0.151 & $24 \pm 3$ & $23 \pm 4$ & 0.558 & 0.000 & 0.517 \\
\hline & $\begin{array}{l}T \\
60\end{array}$ & $25 \pm 4$ & $23 \pm 3$ & & & & $26 \pm 4$ & $24 \pm 4$ & & & \\
\hline & $\begin{array}{l}\mathrm{T} \\
120\end{array}$ & $26 \pm 4$ & $24 \pm 4$ & & & & $26 \pm 4$ & $25 \pm 4$ & & & \\
\hline
\end{tabular}

Data are mean \pm SD. T0: Fasting, T60 and T120: 60 min and 120 after breakfast.

Time effect: repeated measures ANOVA from T0 to T120. Visit 1: placebo or saxagliptin were given before breakfast (acute effect); Visit 2: placebo or saxagliptin had been given for 3 months (long-term effect).

\section{Figures}




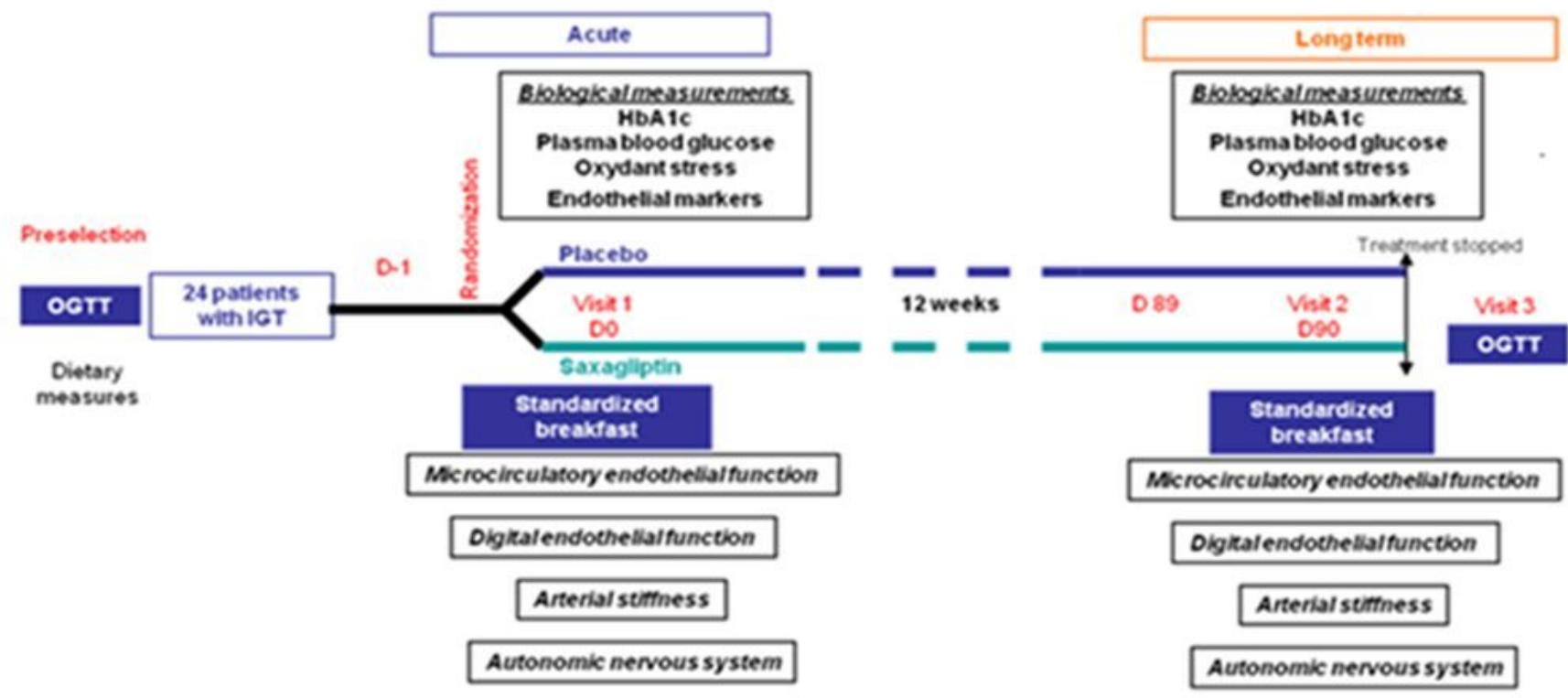

Figure 1

Study protocol D: day; IGT: impaired glucose tolerance; OGTT: oral glucose tolerance test

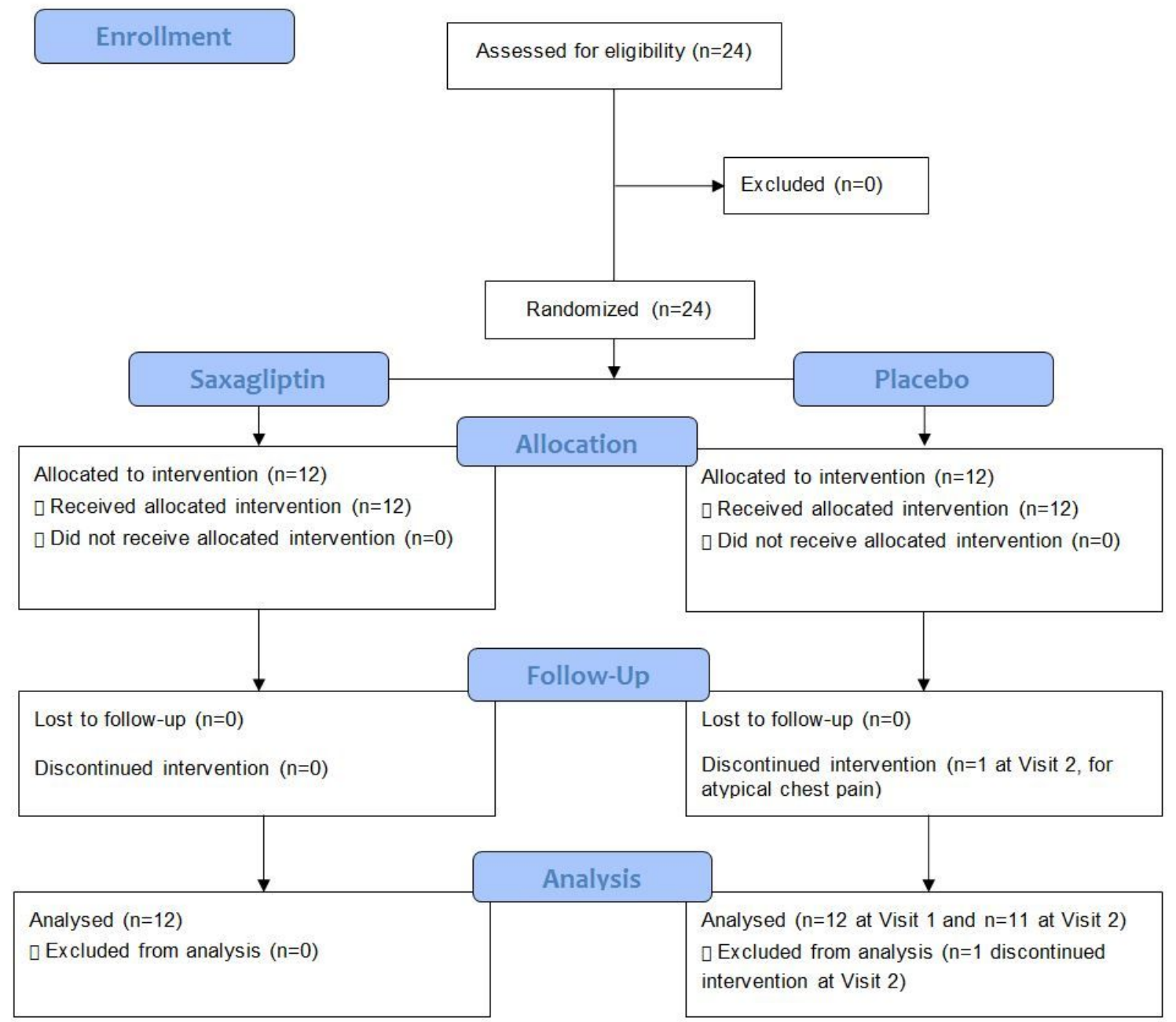


Flow chart of the study
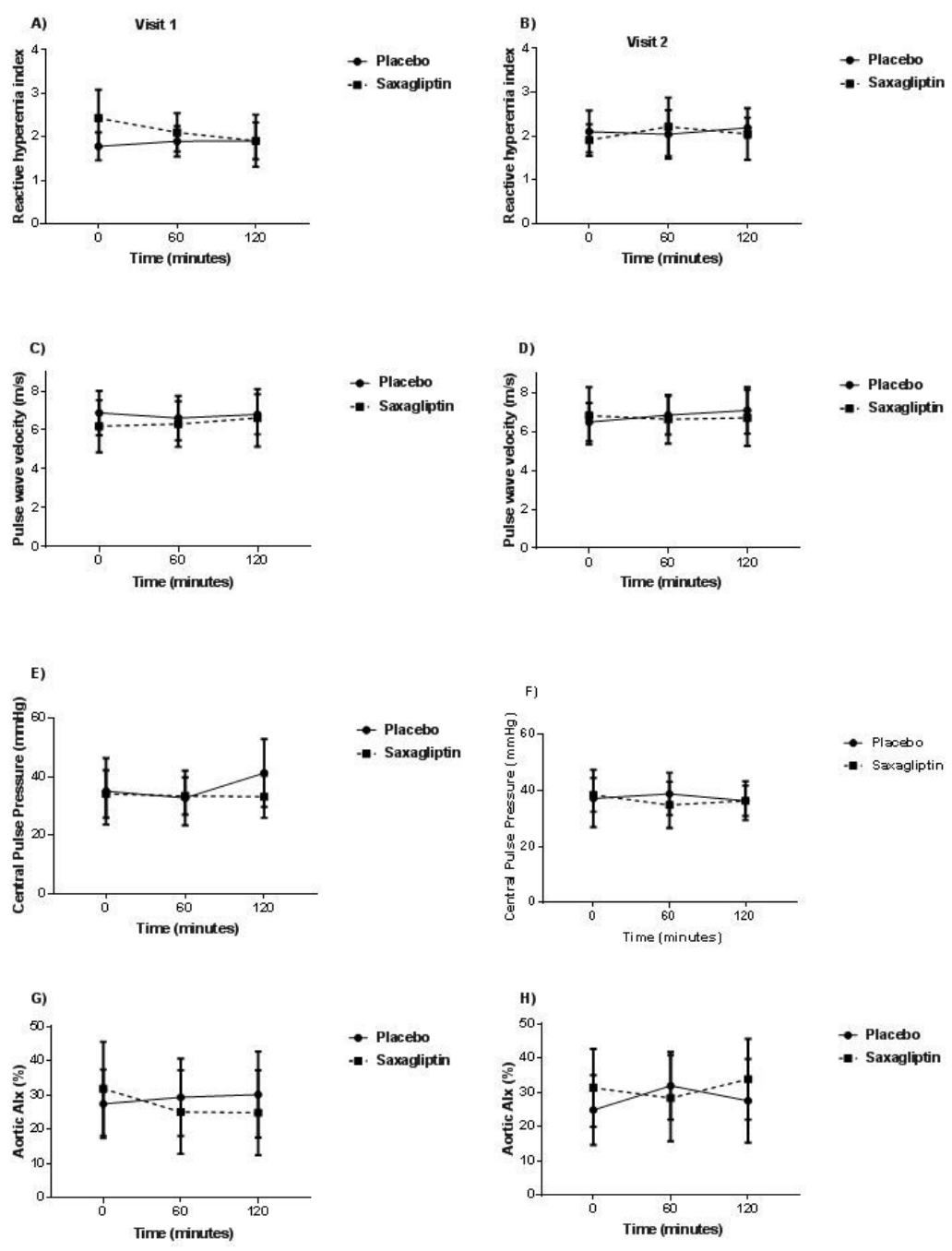

\section{Figure 3}

Arterial endothelial function, pulse wave velocity and central pulse pressure before and after breakfast at Visit 1 and 2 Visit 1: placebo or saxagliptin were given before breakfast (acute effect); Visit 2: placebo or saxagliptin had been given for 3 months (long-term effect) T0: at fast; T60 and T120: 60 and 120 min after breakfast, respectively. A) Reactive Hyperhemia Index at fasting and after breakfast (Visit 1) (between subjects, $p=0.06$, time effect $p=0.16$, interaction time treatment $p<0.01)$ B) Reactive Hyperhemia Index at fasting and after breakfast (Visit 2) (between subjects, $p=0.79$, time effect $p=0.71$, interaction time*treatment $p=0.25$ ) C) Pulse Wave Velocity at fasting and after breakfast (Visit 1 ) (between subjects, $p=0.36$, time effect $p=0.23$, interaction time*treatment $p=0.74$ ) D) Pulse Wave Velocity at fasting and after breakfast (Visit 2) (between subjects, $p=0.84$, time effect $p=0.11$, interaction time*treatment $p=0.34$ ) E) Central Pulse Pressure at fasting and after breakfast (Visit 1) (between subjects, $p=0.33$, time effect $p=0.20$, interaction time*treatment $p=0.11$ ) F) Central Pulse Pressure at fasting and after breakfast (Visit 2) (between subjects, $p=0.47$, time effect $p=0.70$, interaction time ${ }^{\star}$ treatment $p=0.18$ ) G) Aortic Augmentation Index at fasting and after breakfast (Visit 1) (between subjects, $p=0.81$, time effect $p=0.53$, interaction time ${ }^{\star}$ treatment $\left.p=0.06\right) \mathrm{H}$ ) Aortic Augmentation Index at fasting and after breakfast (Visit 2) (between subjects, $p=0.56$, time effect $p<0.005$, interaction time ${ }^{\star}$ treatment $p=0.93$ ) 

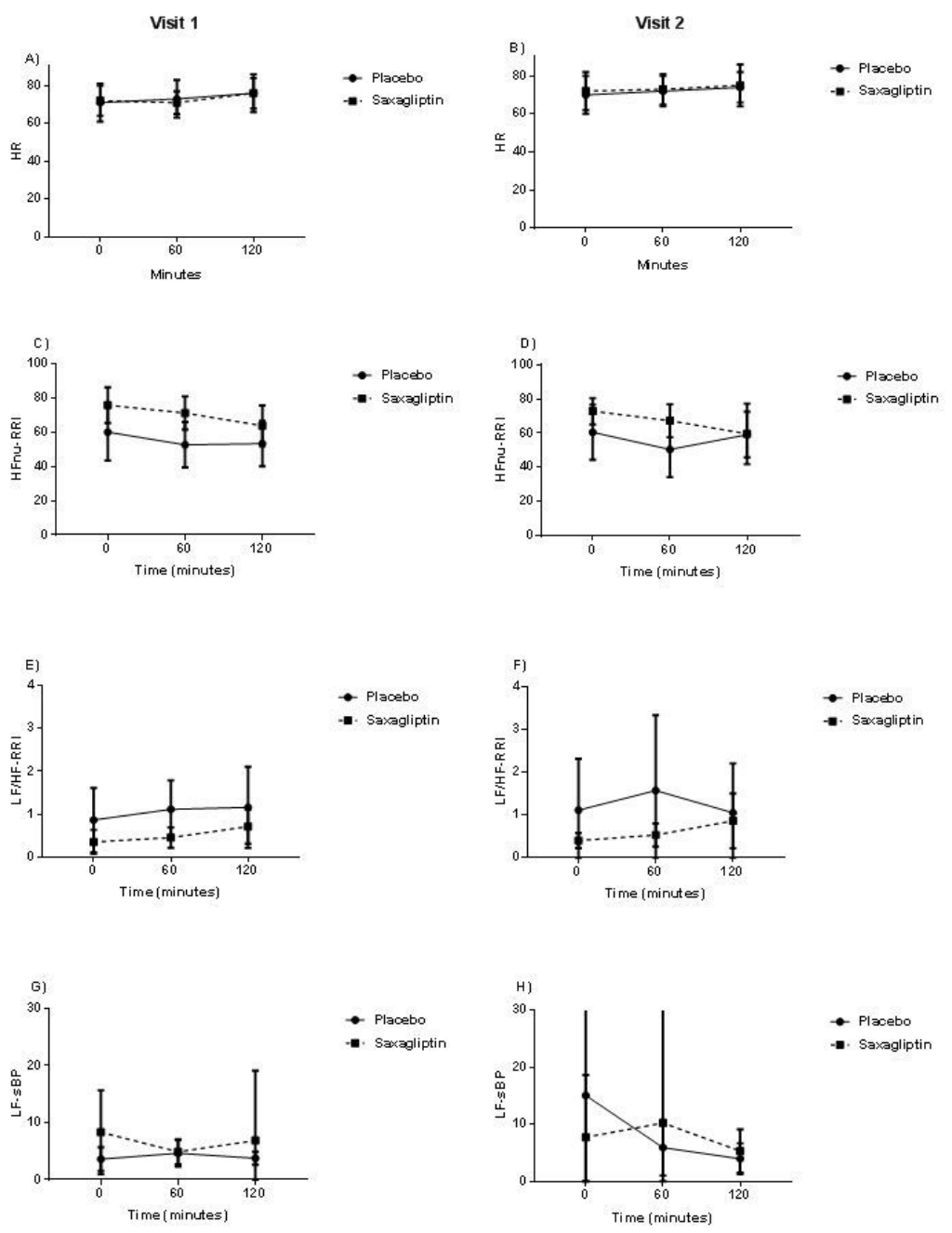

\section{Figure 4}

Cardiovascular autonomic nervous activity at fasting and after breakfast during Visit 1 and Visit 2 HR: Heart rate; HFnu-RRI: cardiac vagal function; LF/HF-RRI: cardiac sympatho-vagal balance; LF-SBP: vascular sympathetic activity Visit 1: placebo or saxagliptin were given before breakfast (acute effect); Visit 2: placebo or saxagliptin had been given for 3 months (long-term effect) A) Heart rate at fasting and after breakfast (Visit 1 ) (between subjects, $p=0.780$, time effect $p<0.0001$, time*treatment interaction $p=0.401$ ) B) Heart rate at fasting and after breakfast (Visit 2) (between subjects, $p=0.794$, time effect $p=0.022$, time*treatment interaction $p=0.748)$ C) Vagal activity at fasting and after breakfast (Visit 1) (between subjects, $p<0.004$, time effect $p<0.0001$, time ${ }^{\star}$ treatment interaction $p=0.464) D$ ) Vagal activity at fasting and after breakfast (Visit 2) (between subjects, $p=0.047$, time effect $p<0.005$, time*treatment interaction $p=0.016)$ E) Sympatho-vagal balance at fasting and after breakfast (Visit 1) (between subjects, $p=0.047$, time effect $p=0.022$, time ${ }^{\star}$ treatment interaction $p=0.365)$ F) Sympatho-vagal balance at fasting and after breakfast (Visit 2) (between subjects, $p=0.097$, time effect $p=0.326$, time ${ }^{\star}$ treatment interaction $p=0.055) G$ ) Vascular sympathetic activity at fasting and after breakfast (Visit 1 ) (between subjects, $p=0.960$, time effect $p=0.042$, time*treatment interaction $\mathrm{p}=0.828) \mathrm{H}$ ) Vascular sympathetic activity at fasting and after breakfast (Visit 2) (between subjects, $p=0.998$, time effect $p=0.231$, time*treatment interaction $p=0.232)$ 